\title{
HORIZONTES DE LA INFORMACIÓN PÚBLICA
}

\section{Horizons of public information}

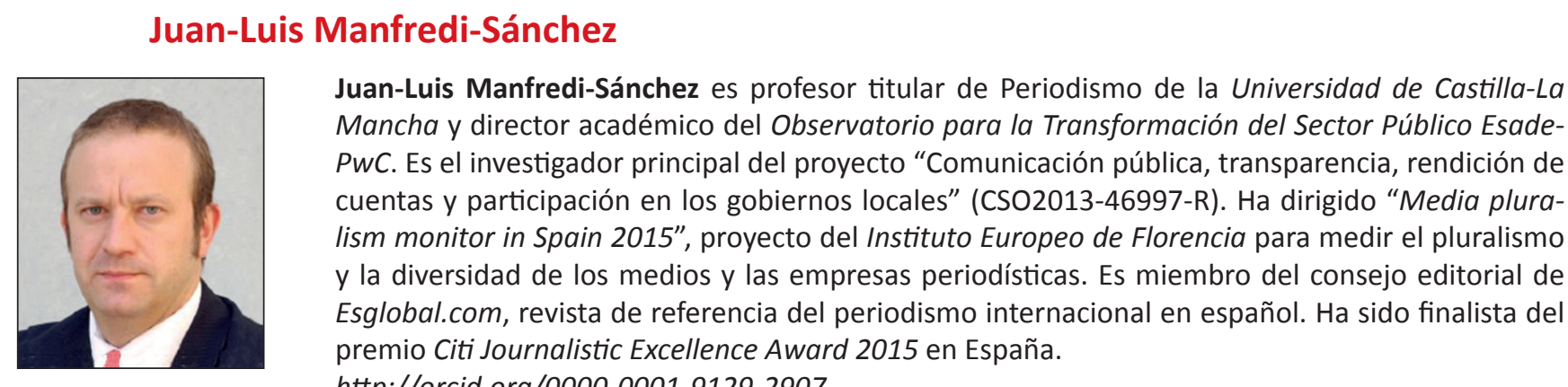
http://orcid.org/0000-0001-9129-2907

Universidad de Castilla-La Mancha, Facultad de Periodismo Campus universitario, s/n. 16071 Cuenca, España juan.manfredi@uclm.es

\section{Resumen}

La información pública es uno de los temas principales de la investigación académica y el desarrollo profesional a través del derecho al acceso y la transparencia. Afecta a tres niveles epistemológicos. A saber, el encaje constitucional, la gobernanza y el ejercicio de la ciudadanía mediática. Interesa en la medida que encontramos una fuerte tensión entre transparencia y confidencialidad, dentro del proceso de reconstrucción de la confianza en la esfera pública. Con estos elementos, podemos adivinar nuevas áreas de trabajo como el proceso de calidad de los datos, la alfabetización, la integridad y la trazabilidad de los datos y la aparición de nuevas profesiones en la comunicación pública.

\section{Palabras clave}

Información pública; Transparencia; Gobernanza; Periodismo; Participación; Derecho al acceso; Gestión pública.

\begin{abstract}
Public information, including the right to know and the right to transparency, is one of the main topics in academic research and professional development. It is usually analyzed on three epistemological levels: constitutional, governance, and media citizenship. It is thought-provoking to the extent that we find a strong tension between transparency and confidentiality, when rebuilding trust in the public sphere. Using this information we can predict new areas of work, such as the quality data processes, literacy, integrity, and traceability of such data and the emergence of new professions in public communications.
\end{abstract}

\section{Keywords}

Public information; Transparency; Governance; Journalism; Participation; Right to know; Public management.

Manfredi-Sánchez, Juan-Luis (2017). “Horizontes de la información pública”. El profesional de la información, v. 26, n. 3, pp. 353-360.

https://doi.org/10.3145/epi.2017.may.01

\section{El tema (informativo) de nuestro tiempo}

La información pública se ha convertido en uno de los temas de nuestro tiempo académico e informativo. El auge de las leyes de transparencia, el debate sobre las filtraciones, la crisis fiscal que ha reducido presupuestos e iniciativas y que obliga a fijar prioridades estratégicas, la consolidación del periodismo de datos sobre asuntos públicos (sanidad, precios de la vivienda, recaudación de impuestos, sobrecoste de infraestructuras), la ejemplaridad de los dirigentes políticos y sociales, o la redefinición de la privacidad y la protección de datos personales, aparecen de manera recurrente en la bibliografía científica y en prensa. Le ha llegado su momento. 
El fundamento de la transparencia encuentra acomodo en tres niveles epistemológicos:

1.1.) En el plano constitucional, el acceso a la información es el desarrollo natural del ejercicio de los derechos individuales de la esfera pública. El acceso actúa como precondición al ejercicio de otros derechos y como fuente de ciudadanía política. Influye sobre el criterio y sobre la capacidad de ejercer los derechos humanos. La Corte Interamericana de Derechos Humanos lo reconoce como tal en la sentencia del 19 de septiembre de 2006 (Claude Reyes y otros vs Chile).

http://www.corteidh.or.cr/docs/casos/articulos/seriec_151_ esp.pdf

En ella integra la libertad de pensamiento y de expresión con la de acceso a la información, en la medida que sin ésta no son posibles aquellas. La obligación positiva corresponde al Estado u organización pública sin que medie acreditación del interés o afectación del individuo.

El rango normativo es discutido en la bibliografía académica. Piñar-Mañas (2014) considera que la Ley 19/2013, de 9 de diciembre, de transparencia, acceso a la información pública y buen gobierno debería haber configurado el derecho al acceso como un derecho fundamental y no solamente como un principio de actuación. Para Guichot (2014, p. 22), existe

"consenso jurídico mundial acerca de la naturaleza iusfundamental del derecho de acceso a la información pública".

Cotino-Hueso (2017) considera que el derecho entronca con el ordenamiento supranacional, tanto por la vía de la Carta de los derechos fundamentales de la Unión Europea en su artículo 42 como en la nueva sentencia del Tribunal Europeo de Derechos Humanos. En el caso Magyar Helsinki Bizottság vs Hungría, de fecha 8 de noviembre de 2016, se establece que la negativa a proveer de información a una organización no gubernamental supone el bloqueo del ejercicio a la libertad de expresión y es manifiestamente contrario al artículo 10 de la Convención Europea de Derechos Humanos. http://www.helsinki.hu/en/magyar-helsinki-bizottsag-vhungary

No es tanto el rango de la norma como el conjunto de instrumentos ágiles para su ejercicio efectivo

Dicho bloqueo erosiona el debate en un asunto de interés público. Torres-Díaz (2013) va en esta línea cuando señala que el derecho al acceso a Internet promueve un nuevo espacio de convivencia de las ideas y el pensamiento crítico. Rubio y Blanes (2014) sostienen que no importa tanto su carácter fundamental como el refuerzo por la vía legislativa. Si se regula, tendría que adquirir rango de ley orgánica y limitaría el desarrollo en otros niveles administrativos. Presenta ventajas inequívocas como el recurso de amparo ante el Tribunal Constitucional o procedimiento sumario y preferente, si bien éstos pueden subsanarse mediante mecanismos sólidos de tutela y garantía. Así, no es tanto el rango de la norma como el conjunto de instrumentos ágiles para su ejercicio efectivo, vinculado a otros derechos fundamentales y libertades públicas.

La tercera vía intelectual vincula este desarrollo con otros derechos fundamentales para los que el acceso es esencial. Sin el principio activo de la transparencia, no cabe la libertad de expresión (artículo 20 CE) o el derecho al acceso (artículo 105 CE).

1.2.) En perspectiva política, es el cimiento de la gobernanza del sector público y privado. Ante sus electores, los responsables explican los resultados de las políticas de gobierno, investigan las demandas sociales de gestión y cambio, proponen programas de actuación o comparten inquietudes de otra naturaleza. Los ciudadanos evalúan como consideran el grado de cumplimiento de las promesas electorales o el desarrollo de las políticas públicas y votan en un sentido $u$ otro.

\section{La decisión política de abrir, compartir y mostrar la información tiene efectos económicos}

La decisión política de abrir, compartir y mostrar la información tiene efectos económicos. Reduce los costes de ejecución de las políticas públicas, incrementa la competencia entre proveedores, facilita el ciclo de gestión y control organizativo de los servicios prestados, al tiempo que crea valor público. Se reducen los costes de transacción económica y se incrementa la seguridad jurídica, clave de la gobernanza en aquellas industrias y servicios con activos específicos que requieren una fuerte inversión, dependen del regulador y colaboración pública y privada. La energía, las infraestructuras, el transporte o crecientes áreas de la salud pública son ejemplos recurrentes. En otras áreas, se consolida la compra pública innovadora como mecanismo de reducción de costes, resolución efectiva de problemas sociales y apuesta por el cambio en la provisión de servicios.

La reutilización de la información tiene otra dimensión económica. Open Data Institute o Thegovlab.com recogen distintas previsiones de cálculo de la liberación de datos de naturaleza pública en forma de datos reutilizables. En el entorno de la UE, podría beneficiar en un incremento del 1,5\% del PIB, mientras que a escala global podría llegar al 4,1\%.

El apagón estadístico o la arbitrariedad de los datos publicados son síntomas de baja calidad democrática, más aún en sociedades digitales. El teléfono, internet, la televisión digital o los dispositivos móviles son canales suficientes para ofrecer un servicio detallado. En último término, el desarrollo instrumental de la transparencia opera como mecanismo preventivo de la corrupción. Cuando se sistematiza la publicación de información producida por la administración (contratos, concesiones, subvenciones, asignaciones) se reducen las posibilidades de empleo patrimonial por parte de la elite burocrática o de los dirigentes políticos. La transparencia apalanca la neutralidad de la administración, promueve sistemas de control y crea barreras a la corrupción (Villoria-Mendieta, 2000). La transparencia contribuye a la expansión de los nuevos valores de la gestión pública; a 
saber, la racionalidad económica y la creación de valor público, la responsabilidad por los resultados y no sólo de los procedimientos, la voluntad de colaboración con otros actores, y la protección del patrimonio público (Longo, 2010).

\section{La reutilización de la información en el entorno de la UE podría aumentar el PIB en $1,5 \%$}

1.3.) El paradigma ciudadano es de carácter reflexivo. Innerarity (2011) ha descrito el valor de la información ordenada, sistematizada para crear conocimiento, en un entorno de creciente complejidad. El avance científico y tecnológico no se acompaña de progreso social, si no somos capaces de entender las consecuencias de las decisiones que tomamos en la esfera pública. En la medida en que la ciudadanía está informada, mejora la calidad de la opinión pública, se incrementa la capacidad de comprender y decidir con mayor libertad, se estimula el pensamiento crítico, se recupera la confianza en las instituciones cuya gestión se ha delegado mediante un sistema de elección, se rinden cuentas de los gastos e inversiones, se engrasa la relación entre administradores y administrados. La idea de ciudadanía informada amerita una transformación sobre la dinámica y el alcance de la administración pública, la vida pública y las organizaciones políticas. La transparencia, como resultado de la información pública y el derecho al acceso, conforma una cultura cívica que no se circunscribe a la legislación y el desarrollo normativo. El profesional de la información actúa en este plano como el intermediario, el traductor del discurso burocrático en una serie de mensajes que informan, evalúan y favorecen la comprensión del sistema administrativo. La accesibilidad a la información y el apoyo de la participación ciudadana plural sustancian la función pública de la información.

\section{El desarrollo instrumental de la transpa- rencia opera como mecanismo preventi- vo de la corrupción}

\section{Escenarios de gestión}

La cantidad, el volumen y la variedad de expedientes, registros y datos se ha multiplicado en los últimos quince años por la concatenación de cambios tecnológicos, políticos y ciudadanos. La frecuencia de actualización de las bases de datos, la digitalización de los procesos de recopilación y difusión, la sistematización de las transacciones automáticas (banca, finanzas, cadenas de suministro) o bien la propia producción individual a través de dispositivos móviles ha multiplicado las fuentes y las instituciones que producen documentos.

La difusión masiva de datos públicos conduce a dos nuevos escenarios de gestión y análisis:

2.1.) El primero consiste en la confusión conceptual entre secreto, confidencial y transparencia, tres grados de ad- ministración de la información. No toda documentación puede ser publicada sin filtros (estado de las negociaciones colectivas, historiales clínicos, certificados de antecedentes penales), ni todas las administraciones funcionan de igual modo. Bien sea por la descentralización o el reparto de competencias entre estos mismos niveles de administración pública, la complejidad de la recopilación, la custodia y la distribución de los datos genera situaciones contradictorias. Tiene efectos en la creación de los sistemas y las redes interadministrativas porque se requieren estándares de intercambio directo, bases de datos compartidas, centro de servicios compartidos que armonicen los procesos y el establecimiento de formas permanentes de cooperación (Colet, 2008).

El profesional de la información actúa como el intermediario, el traductor del discurso burocrático en una serie de mensajes que informan, evalúan y favorecen la comprensión del sistema administrativo

En mi opinión, las deliberaciones pueden requerir cierto grado de discreción para que se genere la confianza entre las partes negociadoras. Apuntar cada hito de la conversación para su publicación no crea un clima de confianza, sino al contrario. Porque habrá que ceder en unos campos para ganar en otros; no hay negociación democrática de suma cero. En cambio, los resultados de las negociaciones, los contratos públicos, las concesiones, los presupuestos y la contabilidad, la financiación de los partidos y otras instituciones similares (colegios profesionales, sindicatos), los órdenes del día y los acuerdos de los órganos de gobierno, la especificidad de la gestión municipal o las consecuencias de los tratados internacionales tienen que ser transparentes, accesibles a la ciudadanía para que el control social y político de la rendición de cuentas sea eficiente.

La actitud del legislador ante la confusión conceptual no contribuye al esclarecimiento. Por un lado, persigue la revelación o cesión de secretos industriales de acuerdo con el código penal. En esta línea preventiva, la Agencia de Protección de Datos considera que los buzones abiertos pueden poner en peligro información protegida.

Por otro, promueve la creación de mecanismos de delación de comportamientos contrarios a la legislación. La Agencia Tributaria, la Inspección de Trabajo y Seguridad Social, la Comisión Nacional de Mercados y Competencia (CNMC) y la Comisión Nacional de Mercados y Valores (CNMV) se han dotado de instrumentos. Las informaciones anónimas recibidas por la Agencia Tributaria suman 12.555 denuncias -un incremento del $27 \%$ anual- por valor de 116 millones de euros, mientras que la Inspección de Trabajo ha conseguido normalizar las denuncias (Carreño-Bravo, 2017). En Europa, la Comisión Europea promueve un buzón para la denuncia de malas prácticas empresariales a través de la encriptación de mensajes. 
La delación afecta a los archivos de carácter público y no existe consenso. Bien es un héroe de la lucha contra el fraude de las multinacionales, una suerte de Robin Hood, o bien un traidor a la patria que revela secretos del contraespionaje, a la manera de Kim Philby. La obtención lícita o no de los datos y el lucro que se obtiene de la delación son debates recurrentes con enfoques diferentes en redes sociales y en la prensa convencional (Qin, 2015).

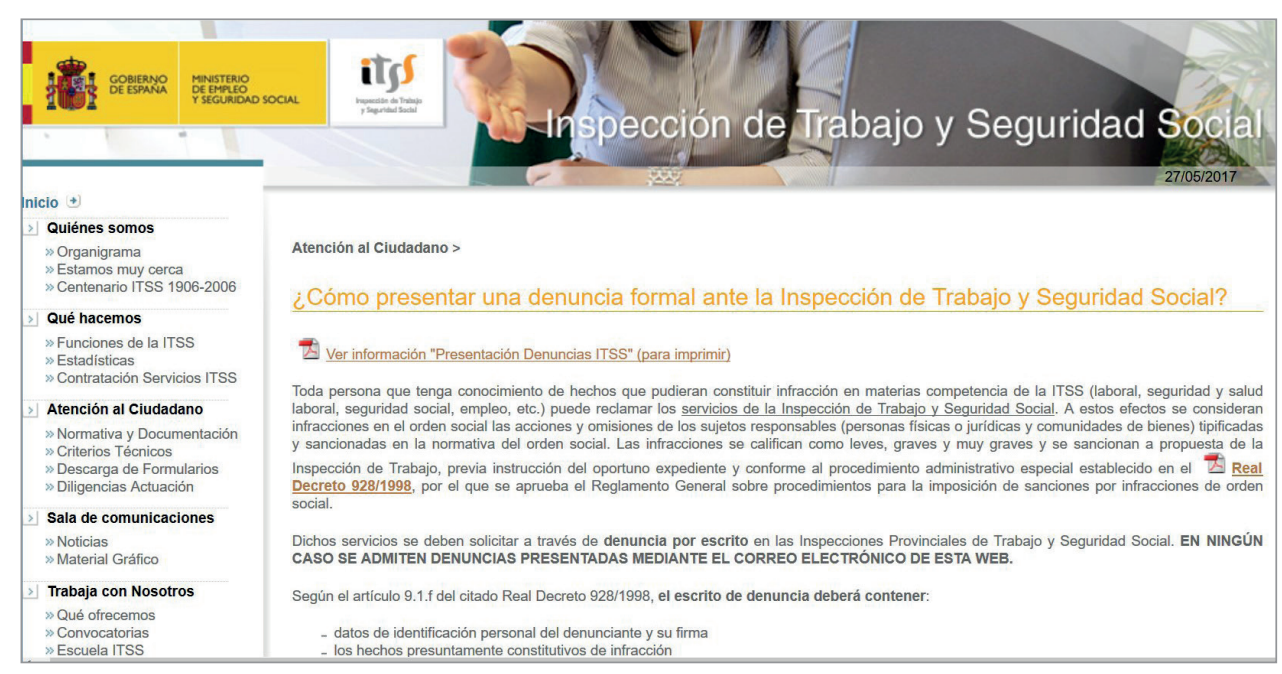

http://www.empleo.gob.es/itss/web/Atencion_al_Ciudadano/COMO_DENUNCIAR_ITSS.htmI

\section{2.) El segundo escenario}

consiste en la reconstrucción de la confianza en las instituciones y el sistema democrático liberal. La recuperación del crédito invita a una nueva arquitectura de las relaciones entre el Estado, el sector privado y la sociedad civil. Prima la lógica de la colaboración, el nuevo reparto de roles, tareas y responsabilidades (Mendoza; Vernis, 2008). La administración pública, en sus distintos niveles, es ahora una impulsora del cambio y no tanto la productora principal de los servicios o infraestructuras de las necesidades sociales.

La divulgación promueve el criterio profesional porque se divulga el mandato de ejecución, los procedimientos, los presupuestos. Se discute sobre el enfoque, el titular de la prestación del servicio o los resultados de las políticas pú- blicas, pero no sobre el diagnóstico con cuentas o datos falseados. Asimismo, actúa como valor moral en la medida en que afecta a las decisiones que se toman en las políticas públicas. Entra en juego aquí la dimensión de ejemplaridad (Gomá-Lanzón, 2009). A través del ejemplo se influye en la vertebración de la ciudadanía. No es el exceso de legislación lo que remedia la corrupción, sino el uso que hacemos de las posiciones de poder, en este caso, la propia información sobre la vida pública. La publicidad activa favorece la gobernanza de las instituciones y la cuenta de resultados, porque introduce la dimensión de funcionamiento previsible de las instituciones.

En este ámbito, la previsión, la planificación y la evaluación de las políticas públicas son requisitos indispensables para la toma de decisiones. La publicidad activa no puede acabar convirtiéndose en un fin en sí mismo, sino en un mecanismo para promover la rendición de cuentas, el seguimiento de la acción de las corporaciones y la medición del grado de cumplimiento de las organizaciones de titularidad pública. La evaluación, sea ex ante o ex post, incrementa la complejidad y la responsabilidad en el ciclo de gestión.

El sistema español se ha dotado de tres instituciones que contribuyen a la evaluación. En materia de intervención, la Autoridad Independiente de Responsabilidad Fiscal (AIReF) tiene como misión la garantía del cumplimiento efectivo del principio de sostenibilidad financiera de las administraciones públicas.

La Agencia Estatal de Evaluación de Políticas Públicas y Calidad de los Servicios (Aeval) mide el impacto de las políticas y los programas públicos. http://www.airef.es

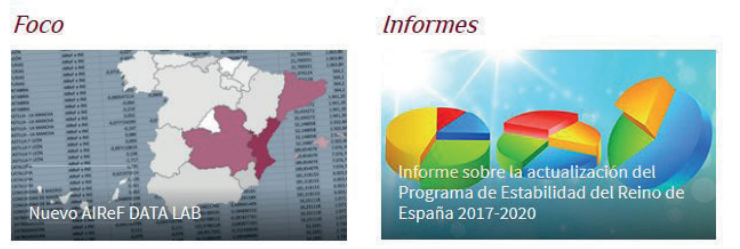


Por último, el Consejo de Transparencia y Buen Gobierno (CTBG) promueve las buenas prácticas en materia de transparencia y contribuye en la educación en materia de acceso. Los tres están adscritos al Ministerio de Hacienda, lo que ha supuesto críticas recurrentes.

El CTBG ha presentado la Metodología de evaluación y seguimiento de la transparencia de la actividad pública (por sus siglas, Mesta) que aspira a convertirse en el modelo español de evaluación del grado de aplicación de la ley en las administraciones públicas, las empresas públicas, las organizaciones políticas, empresariales, sociales y sindicales. Parte de un sistema de autoevaluación que permite la mejora continuada y el ciclo continuo de cumplimiento En otro texto, hemos demostrado cómo la transparencia es una actividad de la administración que se aprende (Manfredi-Sánchez, 2016).

Por último, estos retos de la gestión público y privada requieren una revisión profunda de los formatos de comunicación. El periodismo tiene que replantear cómo se informa y qué instrumentos se acomodan a los nuevos tiempos. La administración ha de proveer documentación usable que facilite el control periodístico y ciudadano.

\section{Nuevas áreas de trabajo profesional e investigación académica}

Se identifican cuatro líneas de investigación.

3.1.) En primer lugar, la avalancha de datos ha colapsado las capacidades institucionales y ciudadanas de recepción, entendimiento y uso de los mismos. Las tres cualidades de los datos masivos se repiten en todos los estudios: volumen, variedad y velocidad. Estas tres $\mathrm{V}$ han orientado el mantra predictivo de las políticas públicas, el comportamiento electoral, las tendencias de consumo, la inteligencia de negocio o la gestión de la crisis, a pesar de que ignoran el ruido. Se necesita desarrollar nuevas habilidades no tanto para la captación de datos, sino para su interpretación, criterio y análisis. Son las tres nuevas V (Gandomi; Haider, 2015): veracidad, variabilidad y valor. Estas pautas se relacionan con la calidad del conocimiento generado y la infraestructura social, no tanto con la creación de más mecanismos de recolección de datos. La inacción ante el cambio en los escenarios de gestión de la información reduce la posibilidad de creación de valor público (Moore, 1998).

3.2.) El segundo reto es la alfabetización digital, en el ejercicio de la ciudadanía mediática. El discurso de los nativos digitales ha ignorado que las competencias digitales se construyen sobre las capacidades y las habilidades preexistentes. El manejo de las tabletas y los dispositivos móviles no supone ninguna ventaja per se $y$, 
menos aún, ante el bombardeo de información imprecisa - o directamente falsa - sobre los asuntos de interés público. La alfabetización evoluciona desde el manejo del terminal hacia una comprensión del entorno digital, la gestión de la privacidad, la veracidad de la información. La alfabetización tiene una dimensión periodística en tanto en cuanto el abuso de los datos sin criterio, la imprecisión deliberada, arruina la confianza pública en las instituciones y el sistema.

3.3.) El tercer desafío consiste en la integridad y la trazabilidad de la documentación que se

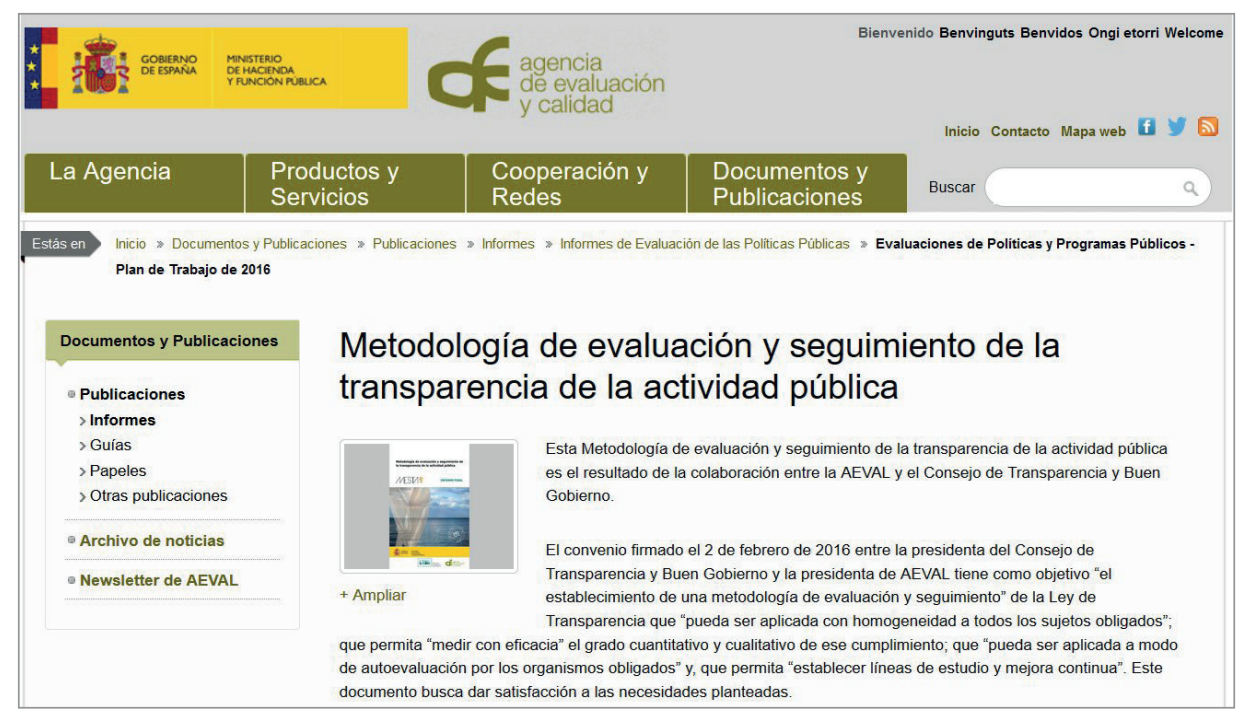

http://www.aeval.es/es/difusion_y_comunicacion/publicaciones/Informes/Informes_de_Evaluacion/ Evaluaciones_2016/E42.html pone a disposición de la ciuda-

danía. En los asuntos públicos, conviene conocer qué grupos de interés han prestado apoyo en una u otra dirección, qué agenda tienen los representantes políticos o qué financiadores han contribuido a una campaña. La trazabilidad permite conocer la evolución de una posición política, el desarrollo legislativo o la influencia ejercida por un grupo de presión. La Comisión Europea, el Ayuntamiento de Madrid o la Comisión Nacional del Mercado de Valores (CNMV) han creado registros de la actividad de lobby, pero no está claro que ese mecanismo sea el único camino para la transparencia en la gestión de los asuntos públicos y la rendición de cuentas.

\section{El sistema español se ha dotado de tres instituciones que contribuyen a la eva- luación: AIReF, Aeval y CTBG}

En particular, crece la preocupación por la rendición de cuentas que prestan las empresas tecnológicas y los algoritmos. Sea por su impacto en el consumo o en los resultados electorales (Allcott; Gentzkow, 2017), cabe una revisión de la protección de los derechos de los usuarios digitales. El tipo de información que manejan es de naturaleza pública (salud, finanzas), aunque se gestione a título privado. El aprovechamiento del flujo de información masivo representa una oportunidad para que los gobiernos operen de manera eficiente y crezcan nuevas industrias y actividades económicas (Pentland, 2015).

3.4.) La cuarta función es la nueva tarea de los profesionales de la información. En la profesión periodística, se plantean dos propósitos preferentes. Apremia la redefinición del servicio a la comunidad lectora y el abandono del periodismo como producto que se compra en el quiosco. El servicio orienta la función sociopolítica y recupera la rendición de cuentas de los poderes públicos y privados. Los denominados rituales de transparencia y su conexión con la credibilidad institucional se han incrementado en los últimos cinco años (Karlsson; Clerwall; Nord, 2014).
La pérdida de credibilidad ha resucitado la mejora de los procesos de verificación. En su dimensión política, la publicación de datos y el acceso a la información pública no ha redundado en mejores prácticas informativas. A menudo, se utilizan esta misma provisión de datos para crear una cascada informativa sin hilo conductor que desorienta a los lectores. La temida post-verdad no es más que la mentira disfrazada de datos a interés de parte.

\section{No es el exceso de legislación lo que remedia la corrupción, sino el uso que hacemos de las posiciones de poder, en este caso, la propia información sobre la vida pública}

En el ámbito de la documentación, la memoria institucional es un instrumento para reducir el conflicto de interés en la evaluación de las políticas públicas, en la administración de los asuntos públicos, en la relación entre instituciones políticas y funcionarios de alto nivel, en la colaboración público-privada y en otras oportunidades de creación de valor público.

Se completa la profesión con nuevos perfiles que mejoren la información visual mediante tablas, infografías, imágenes informadas. El texto ya no es el eje único sobre el que gira la función periodística. Las nuevas narrativas en los móviles y las tabletas responden a las nuevas formas de empresa periodística.

\section{Camino de Ítaca}

Como en el poema de Kavafis, el camino hasta la consolidación como un derecho ciudadano, un mecanismo de rendición de cuentas, un instrumento político, una técnica de gestión y una clave del nuevo periodismo ha sido largo, lleno de aventuras y de conocimientos. Ahora que vislumbramos Ítaca conviene una reflexión final. 
La información pública es una oportunidad para un cambio cultural relevante en la gestión pública, en el periodismo y en el ejercicio de los derechos y las libertades públicas. Hemos cerrado la etapa de titubeos y discusión por la dinámica y el alcance del principio de transparencia y acceso. El establecimiento del ordenamiento jurídico, el crecimiento de las prácticas periodísticas con resultados novedosos y el empoderamiento de la sociedad civil ha conseguido que ambos principios sean troncales en la gobernanza pública. Los procedimientos contribuyen a que la cultura de transparencia se asiente.

Apremia la redefinición del servicio a la comunidad lectora y el abandono del periodismo como producto que se compra en el quiosco

Y veremos más, al menos, en cuatro ejes:

- El primero serán los estudios cualitativos sobre los contenidos elaborados bajo la etiqueta de transparencia, información pública, gobernanza o acceso. El ítem propio de "Perfil del contratante" presenta una homogeneidad que no se encuentra en los anteriores.

- Le sigue a este punto un análisis sobre el perfil técnico de quienes se dedicarán a esta materia. Es un yacimiento de empleo para los profesionales de la información.

- El tercer eje es la evaluación del impacto periodístico de la información. Ya hemos visto cambios, pero veremos más cuando se transformen la simple agregación de documentos en productos y servicios periodísticos. El periodismo puede contribuir a la alfabetización ciudadana mediante la conversión de asuntos complejos en noticias, análisis, entrevistas y otros géneros propios.

- El último punto es el desarrollo lógico. Las ciencias de la documentación en esta materia han evolucionado y lo harán más para atender el cambio en la demanda social.

En suma, este monográfico muestra que estamos ante un período expansivo de la investigación en información y comunicación pública.

\section{Bibliografía}

Allcott, Hunt; Gentzkow, Matthew (2017). "Social media and fake news in the 2016 election". Journal of economic perspectives, v. 31, n. 2, pp. 211-236.

http://web.stanford.edu/ gentzkow/research/fakenews. $p d f$

Blanes-Climent, Miguel-Ángel (2014). La transparencia informativa de las administraciones públicas. Madrid: Aranzadi. ISBN: 9788490593974

Carreño-Bravo, Belén (2017). “Las administraciones públicas impulsan las filtraciones anónimas que la Justicia sigue persiguiendo". Eldiario.es, 21 de marzo de 2017.

http://www.eldiario.es/economia/administraciones-publicasfiltraciones-Justicia-persiguiendo_0_624688323.html

Colet, Enric (2008). "Innovación tecnológica y administración electrónica”. En: Longo, Francisco e Ysa, Tamyko (eds.).
Los escenarios de la gestión pública del siglo XXI. Barcelona: Escola d'Administració Pública de Catalunya, pp. 193-220. http://eapc.gencat.cat/web/.content/home/publicacions/ coleccion_innovacion/1._los_escenarios_de_la_gesti_n_p_ blica_del_siglo_xxi/LOS-ESCENARIOS-baja_DEF.pdf

Cotino-Hueso, Lorenzo (2017). "La consideración del acceso a la información pública como derecho fundamental en España en razón de exigencias supranacionales". Cuadernos constitucionales de la cátedra Fadrique Furió Ceriol, $81 / 82$.

Gandomi, Amir; Haider, Murtaza (2015). “Beyond the hype: Big data concepts, methods, and analytics". International journal of information management, v. 35, n. 2, pp. 137-144. https://doi.org/10.1016/j.ijinfomgt.2014.10.007

Gomá-Lanzón, Javier (2009). Ejemplaridad pública. Madrid: Taurus. ISBN: 9788430606832

Guichot-Reina, Emilio (2014). Transparencia, acceso a la información pública y buen gobierno. Estudio de la Ley 19/2013. Madrid: Tecnos. ISBN: 9788430961665

Innerarity, Daniel (2011). La democracia del conocimiento. Barcelona: Paidós. ISBN: 9788449325670

Karlsson, Michael; Clerwall, Christer; Nord, Lars (2014). "You ain't seen nothing yet: Transparency's (lack of) effect on source and message credibility". Journalism studies, v. 15 , n. 5, pp. 668-678.

https://doi.org/10.1080/1461670X.2014.886837

Longo, Francisco (2010). "Ejes vertebradores de la gobernanza en los sistemas públicos. Un marco de análisis en clave latinoamericana". Revista del CLAD Reforma y Democracia, n. 46, pp. 73-102.

http://itemsweb.esade.edu/idgp/longo.pdf

http://old.clad.org/portal/publicaciones-del-clad/revistaclad-reforma-democracia/articulos/046-febrero-2010/longo

Manfredi-Sánchez, Juan-Luis (2016). "A major disappointment: The quest for transparency among Spanish municipalities". International journal of media and cultural politics, v. 12, n. 2, pp. 265-269.

https://goo.gl/GTYO2T

https://doi.org/10.1386/macp.12.2.265_7

Mendoza, Xavier; Vernis, Alfred (2008). "The changing role of governments and the emergence of the relational state". Corporate governance. The international journal of business in society, v. 8, n. 4, pp. 389-396.

https://doi.org/10.1108/14720700810899130

Moore, Mark H. (1998). Gestión estratégica y creación de valor en el sector público. Barcelona: Paidós. ISBN: 84493 05845

Pentland, Alex (2015). Social physics: How social networks can make us smarter. New York: Penguin House. ISBN: 9780143126331

Piñar-Mañas, José-Luis (2014). "Transparencia y derecho de acceso a la información pública: algunas reflexiones en torno al derecho de acceso en la Ley 19/2013, de transparencia, acceso a la información y buen gobierno". Revista catalana de dret públic, n. 49, pp. 1-19. 
http://revistes.eapc.gencat.cat/index.php/rcdp/article/ view/10.2436-20.8030.01.29/n49-pinar-es.pdf

Qin, Jie (2015). "Hero on Twitter, traitor on news. How social media and legacy news frame Snowden". The international journal of press/politics, v. 20, n. 2, pp. 166-184. https://doi.org/10.1177/1940161214566709

Rubio, Rafael (2015). "Transparencia y rendición de cuentas, de las leyes de transparencia a los reglamentos". En: Calderón, César (coord.). Guía práctica para abrir gobiernos. Manual de "open government" para gobernantes y ciudadanos. Madrid: Instituto Universitario de investigación Ortega y Gasset, pp. 41-66. http://www2.congreso.gob.pe/sicr/cendocbib/con4_uibd.nsf/ FOCE9C642E7BC17205257F1400075324/SFILE/get_file.pdf

Torres-Díaz, Concepción (2013). "El derecho de acceso a Internet como derecho fundamental: análisis constitucional desde una perspectiva crítica". En: Corredoira-Alfonso, Loreto y Cotino-Hueso, Lorenzo (eds.). Libertad de expresión e información en Internet. Amenazas y protección de los derechos personales. Madrid: Centro de Estudios Políticos y Constitucionales, pp. 3-22. ISBN: 9788425915611

Villoria-Mendieta, Manuel (2000). Ética pública y corrupción. Curso de ética administrativa. Madrid: Tecnos. ISBN: 9788430935840

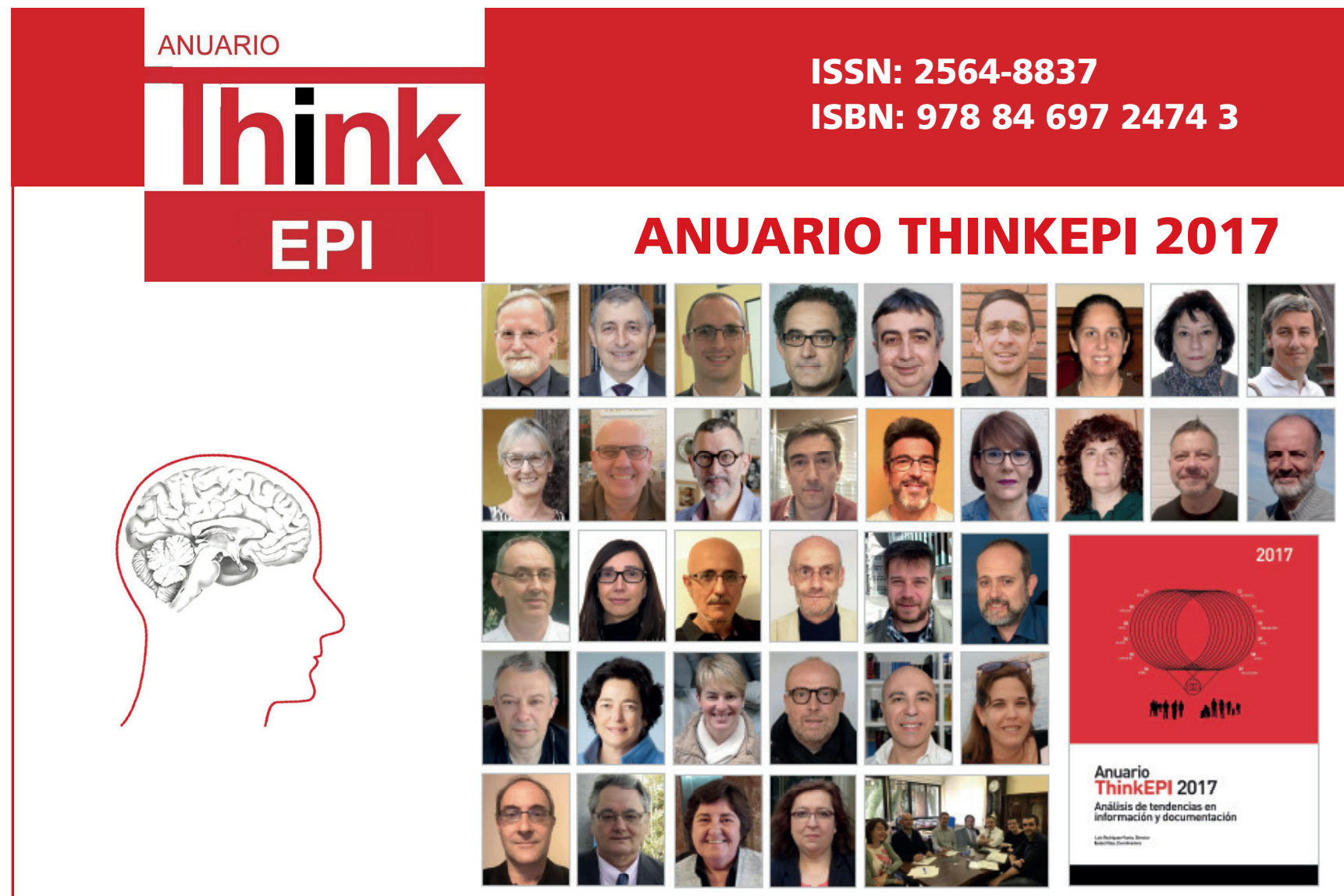

\section{PRECIOS ANUARIO THINKEPI}

Suscripción online (2007-2017)

Instituciones ..................................... $85 €$

Individuos (particulares) ................... $51 €$

Números sueltos

Instituciones

Anuario ThinkEPI 2017 (pdf) ............ $40 €$

Anuario de ańos anteriores ...............20 $20 €$

Individuos (particulares)

Anuario ThinkEPI 2017 (pdf)

Anuario de ańos anteriores
Desde 2014 es posible el acceso mediante suscripción a todos los Anuarios ThinkEPI publicados hasta el momento desde el Recyt de la Fecyt

http://recyt.fecyt. es/index.php/ThinkEPI

\author{
Más información: \\ Isabel Olea \\ epi.iolea@gmail.com
}

